\title{
Breeding Strategies for Improving Rice Yield-A Review
}

\author{
Mudasir Hafiz Khan1*, Zahoor Ahmad Dar², Sher Ahmad Dar ${ }^{2}$ \\ ${ }^{1}$ Department of Agriculture, Lal Mandi, Srinagar (J\&K) \\ ${ }^{2}$ Division of Plant Breeding and Genetics, S. K. University of Agricultural Sciences \& Technology of Kashmir, \\ Shalimar Campus, Srinagar (J\&K) \\ Email: drmhkhan8@gmail.com
}

Received 21 January 2015; accepted 18 May 2015; published 22 May 2015

Copyright (C 2015 by authors and Scientific Research Publishing Inc.

This work is licensed under the Creative Commons Attribution International License (CC BY). http://creativecommons.org/licenses/by/4.0/

(c) (i) Open Access

\section{Abstract}

An increase in productivity is always one of the main goals of any crop breeding program including rice. However, many goals can be identified for this crop varying in importance from region to region, country to country, and even within a given country. Increase in grain yield potential is the major goal of almost all rice breeders programs. The major impacts are related to the development of new strategies to increase the genetic grain yield potential of the varieties. Rice breeders have been very successful in improving the crop. Some milestones are the contribution to the green revolution with the semi-dwarf varieties, the new rice plant type and hybrid rice. The main breeding method used to improve rice is the pedigree, but development of hybrids and population improvement are added to the breeder's portfolio. Breeders have been taking advantage of biotechnology tools to enhance their breeding capacity; however, many programs are still struggling on how to integrate them into the breeding programs and how to balance the allocation of resources between conventional and modern tools.

\section{Keywords}

Rice, Hybridization, Ideotype, Heterosis, Male Sterility, Wide Hybridization, Genetic Engineering, MAS Breeding

\section{Introduction}

Rice (Oryza sativa $\mathrm{L} ., 2 \mathrm{n}=2 \mathrm{x}=24$ ) is second most widely grown cereal crop and the staple food for more than half of world's population, providing two thirds of calorie intake for more than three billion people in Asia and one-third of calorie intake of nearly 1.5 billion people in Africa and Latin America. It is probably a descendent of wild grass that was most likely cultivated in the foothills of the far Eastern Himalayas. Some believes that the 
rice plant may have originated in southern India, then spread to the north of the country and then onwards to China. It then arrived in Korea, the Philippines (about 2000 B. C.) and then Japan and Indonesia (about 1000 B. C.). When Alexander the Great invaded India in 327 B. C., it is believed that he took rice back to Greece. Arab travellers took it to Egypt, Morocco and Spain and that is how it travelled all across Europe. Portugal and Netherlands took rice to their colonies in West Africa and then it travelled to America through the "Columbian Exchange" of natural resources. But as is traditionally known, rice is a slow starter and this is also true to the fact that it took close to two centuries after the voyages of Columbus for rice to take root in the Americas. Thereafter the journey of rice continues with the Moors taking it to Spain in 700 A. D. and then the Spanish brought rice to South America at the beginning of 17th century.

The average growth rate of rice yield was $3.68 \%$ per year in the early 1980 's but has decreased to $0.74 \%$ per year in the late 1990's. Top ten rice producing countries are given in Table 1. China and India together produced $364.73 \mathrm{~m} \cdot \mathrm{t}$ from an area of $74.60 \mathrm{~m} \cdot \mathrm{ha}$. However, the average productivity of China (6.72 t/ha) is much higher than that of India (3.61 t/ha).

In India rice provides $43 \%$ of calorie requirement for more than $70 \%$ of population. Ten states of India contributed 77.49\% (816.11 Lt) of total rice production during 2012 (Table 2). The largest production of $146.06 \mathrm{Lt}$ came from West Bengal followed by 140.22 Lt from UP and 128.95 Lt from Andhra Pradesh.

Table 1. Top ten rice producing countries of world.

\begin{tabular}{ccccc}
\hline S No. & Country & Rice Production $(000 \mathrm{t})$ & Area $(000 \mathrm{ha})$ & Yield (t/ha) \\
\hline 1 & China & 205,714 & 30,600 & 6.72 \\
2 & India & 159,016 & 44,000 & 3.61 \\
3 & Indonesia & 59,370 & 12,160 & 4.88 \\
4 & Vietnam & 44,480 & 7780 & 5.72 \\
5 & Thailand & 31,061 & 10,900 & 2.85 \\
6 & Myanmar & 18,984 & 7065 & 3.69 \\
7 & Philippines & 19,365 & 4890 & 3.96 \\
8 & Brazil & 12,500 & 2450 & 5.10 \\
9 & Japan & 10,577 & 1590 & 6.65 \\
\hline
\end{tabular}

Source: USDA 2014.

Table 2. Top ten rice producing states of India.

\begin{tabular}{ccccc}
\hline S.No & Country & Rice Production (Lt) & Area (Lha) & Yield (t/ha) \\
\hline 1 & West Bengal & 146.06 & 54.34 & 2.69 \\
2 & Andhra Pradesh & 128.95 & 40.96 & 3.15 \\
3 & Uttar Pradesh & 140.22 & 59.47 & 2.36 \\
4 & Punjab & 105.42 & 28.18 & 3.74 \\
5 & Orissa & 58.07 & 44.45 & 3.31 \\
6 & Tamil Nadu & 74.59 & 19.04 & 1.34 \\
7 & MP & 22.27 & 16.62 & 2.15 \\
9 & Bihar & 71.63 & 33.24 & 3.04 \\
& Haryana & 37.59 & 12.35 & 2.13 \\
\hline
\end{tabular}




\section{Rice Production in Jammu and Kashmir}

In the State of Jammu \& Kashmir, rice being the principal food crop, is cultivated across diverse agro-ecological situations extending from sub-tropical region (>1000 m·asl) of Jammu to temperate cold high altitude areas (1800 - $2500 \mathrm{~m} \cdot \mathrm{asl})$ of Kashmir. The trends in area, production and productivity over years are presented in Figure 1. During 2012, $5.45 \mathrm{Lt}$ of rice was grown from 2.63 L·ha with an average yield of about $2.07 \mathrm{t} / \mathrm{ha}$. In Kashmir the production environment is typically temperate, with cold winters and mild summers, characterized by short growing season, long days, cool nights and occurrence of wide differences between maximum and minimum temperatures. Compared with average yield of temperate regions of world (5.8 t/ha), the rice productivity is disappointingly very low (2.5 t/ha) in Kashmir. The rice area in Kashmir can be broadly categorized into two distinct zones with entirely different agro-climatic conditions. The higher belts, comprising areas between 1800 - $2500 \mathrm{~m} \cdot a s l$, constitute $10 \%$ - 12\% of total rice area. The growing season is restricted to 125 - 135 days. Besides cool soil and atmospheric temperatures cold water from melting snow is directly used for irrigation purposes leading to an environmentally handicapped ecology. The lower belt or valley basin enjoys relatively favourable growing conditions of 140 - 145 days and lies between 1500 - $1800 \mathrm{~m} \cdot$ asl. The varietal requirement of two zones is different with Japonica rice being more predominantly grown in upper belts and Indicas in the valley basin.

The ultimate goal of crop breeding is to develop varieties with high yield potential and desirable agronomic characteristics. In rice breeding, the most important qualities sought by breeders have been high yield potential; resistance to major diseases and insects; and improved grain and eating quality. However, there seems to be some conflict between these aims. Emphasis on high grain quality tends to result in unstable yields. Conversely, too much emphasis on disease and insect resistance and stable yields leads to poor grain quality. Hence, breeding efforts should concentrate on varieties with the potential to minimize yield losses under unfavorable conditions, and to maximize yields when conditions are favorable. Various breeding strategies for increasing the yield potential include;

1) Conventional Hybridization

2) Ideotype Breeding

3) Heterosis Breeding

4) Male Sterility

5) Wide Hybridization

6) Genetic Engineering

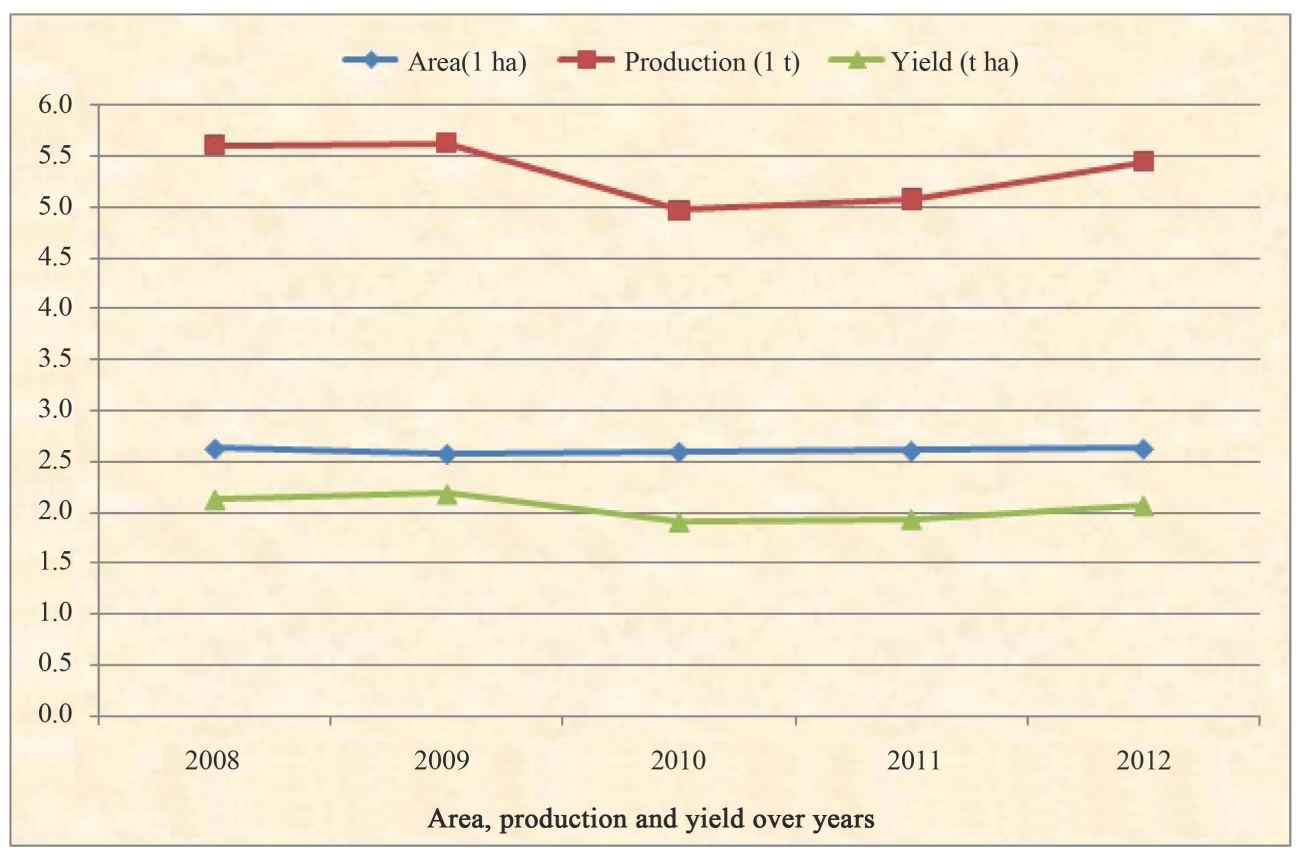

Figure 1. Trends in area, production and yield of rice over years. 
7) Molecular Marker Assisted Breeding

\section{Conventional Hybridization and Selection Procedures}

This is the time tested strategy for selecting crop cultivars with higher yield potential. It has two phases. The first phase involves the creation of variability through hybridization between diverse parents. In the second phase desirable individuals are selected on the basis of field observations and yield trials. It has been estimated that on the average about $1.0 \%$ increase has occurred per year in the yield potential of rice over a 35 year period since the development of first improved variety of rice, IR8 [1]. The yields of crops where there is enough investment in research have been continuously increased and there is no reason why further increases cannot be attained.

\section{Submergence Tolerance through Conventional Breeding Approach}

The traditional rice varieties have evolved suitable mechanism(s) to survive under this stress. Systematic screening of rice germplasm has shown that there are excellent flood-tolerant rice types locally available. Among these are especially the "FR13A" and "FR43B" of India, "Kurkaruppan" of Sri Lanka and "Goda Heenati" of Indonesia. Detailed study on such contrasting rice types has indicated that flooding tolerance is controlled by one or a few genes with major effects and additional genes with smaller, modifying effects. Breeding efforts at IRRI led to evolution of tolerant lines with good agronomic traits. The line "IR 49830-7-2-2" combines high tolerance levels with higher yield potential and resistance to diseases and insect pests and it has been extensively used as a donor parent in the breeding programme. "Sudhir" is another variety which has been developed from the "FR13A" × "Biraj" crosses. This variety has been released by the "Central Variety Release Committee, Indian Council of Agricultural Research, Government of India” in 1999.

In spite of the above developments, till date no variety has been developed which combines desirable levels of flooding tolerance with grain yield. It is attributed to the fact that "FR 13A" is a poor combiner for yield and other agronomic traits. Apart from "FR 13A", "BKNFR 76106-16-0-1-0" and "Kurkaruppan" have major dominant gene for submergence tolerance. Flooding tolerant rice "Goda Heenati" apparently does not have the same submergence tolerance gene. It has been suggested that there are at least three submergence tolerance genes in "FR13A", "Kurkaruppan" and "Goda Heenati". Further, though "FR13A" is considered to be an excellent source of submergence tolerance especially at young seedling stage (10 days), "CN 540 (Suresh)" is found to be more resistant than "FR13A" and "FR43B" might result in genotypes with better submergence tolerance.

Major attempts have also been made in breeding for improved submergence tolerance through the use of double haploid lines (DHLs), developed using crosses between submergence tolerant and sensitive rice cultivars [2]. Two DHL populations for submergence tolerance have been developed at IRRI using the cross combination of 1) "IR $49830 \times$ CT 6241" and 2) "FR13A × IR 42". These populations were evaluated simultaneously in Thailand and Philippines. In Thailand, a distinct bimodal distribution of lines for survival after submergence was observed supporting the concept of a single gene for submergence tolerance [3]. However, the result from Philippines did not support this theory.

Use of DHLs has recently been reported for identification of two RFLP (restriction fragment length polymorphism) markers for submergence tolerance of rice which are mapped to a segment of chromosome 9 . This chromosome segment [Sub 1(t)] accounted for $70 \%$ of the phenotypic variance in submergence tolerance of this population [4]. It would be rewarding if the Sub 1(t) locus is cloned through map-based cloning technique. Recently, a high resolution map has been constructed around the Sub 1(t) locus through the use of RFLP and AFLP (amplified fragment length polymorphism) markers. Present attempts are focused on cloning of tightly-linked AFLP markers for eventual screening of gene libraries [5].

\section{Ideotype Breeding}

Ideotype breeding aimed at modifying the plant architecture is a time tested strategy to achieve increases in yield potential. Thus selection for short statured cereals such as wheat, rice, and sorghum resulted in doubling of yield potential. Yield potential is determined by the total dry matter or biomass and the harvest index (HI). Tall and traditional rice had $\mathrm{HI}$ of around 0.3 and total biomass of about 12 tons per hectare. Thus their maximum yield was 4 tons per hectare. Their biomass could not be increased by application of nitrogenous fertilizers as the 
plants grew excessively tall, lodged badly and the yield decreased instead of increasing. To increase the yield potential of topical rice it was necessary to improve the harvest index and nitrogen responsiveness by increasing the lodging resistance. This was accomplished by reducing the plant height through incorporation of a recessive gene sd1 for short stature.

The first short statured variety IR8, developed at the International Rice Research Institute (IRRI) also had a combination of other desirable traits such as profuse tillering, dark green and erect leaves for good canopy architecture and sturdy stems. It responded to nitrogenous fertilizer much better and had a higher biomass (about 18 tons) and $\mathrm{HI}$ of 0.45 . Its yield potential was 8 - 9 tons per hectare [6].

To increase the yield potential of rice further, a new plant type was conceptualized in 1988. Modern semidwarf rice produce a large number of unproductive tillers and excessive leaf area which cause mutual shading and reduce canopy photosynthesis and sink size, especially when they are grown under direct sowing conditions. To increase the yield potential of these semi-dwarf rice, IRRI scientists proposed further modifications of plant architecture with following characteristics:

$>$ Low tillering, ( 9 - 10 tillers for transplanted conditions)

$>$ No unproductive tillers

$>200$ - 250 grains per panicle

$>$ Dark green, thick and erect leaves

$>$ Vigorous and deep root system

This proposed ideotype became the "New Plant Type" (NPT) highlighted in IRRI's strategic plan [7] and breeding efforts to develop NPT were initiated in 1990. The objective was to develop improved germplasm with $15 \%$ - 20\% higher yield than the existing high yielding varieties. Numerous breeding lines with desired ideotype were developed [8] and shared with the national rice improvement programs. Three NPT lines have been released in China and one in Indonesia. Other NARS are evaluating and further improving NPT lines.

Reference [9] reported that First-generation new plant type (NPT) lines developed from tropical japonica at IRRI did not yield well because of limited biomass production and poor grain filling. Progress has been made in second-generation NPT lines developed by crossing elite indica with improved tropical japonica. Several second-generation NPT lines out yielded the first-generation NPT lines and indica check varieties. China's "super" rice breeding project has developed many F1 hybrid varieties using a combination of the ideotype approach and inter-subspecific heterosis. These hybrid varieties produced grain yield of $12 \mathrm{t}^{\mathrm{t}} \mathrm{ha}^{-1}$ in on-farm demonstration fields, $8 \%$ - 15\% higher than the hybrid check varieties. The success of China's "super" hybrid rice was partially the result of assembling the good components of IRRI's NPT design in addition to the use of intersubspecific heterosis.

The following plant type has been proposed by Chineses scientists to be combined with heterosis breeding to produce super rice hybrids capable of yielding $100 \mathrm{~kg} / \mathrm{ha}$ yield per day.

$>$ Plant height about $100 \mathrm{~cm}$, with culum length of $70 \mathrm{~cm}$.

$>$ Top three leaves;

Long: Flag leaf is $50 \mathrm{~cm}$ and 2nd and 3rd comes $55 \mathrm{~cm}$ in length. The top two leaves are higher than the top of the panicle.

Drect: Leaf angle of the flag, -2nd and -3rd leaves are around 50, 100 and 200, respectively.

$>$ Narrow and V shaped: The leaves look narrow but they are wide when flattened.

Thick: $55 \mathrm{~g} \cdot \mathrm{m}^{-2}$ of specific leaf weight for the top three leaves.

$>$ Plant type: Moderately compact type with moderate tillering capacity; droopy panicles, the panicle top about $60 \mathrm{~cm}$ from the ground after filled; erect leaf callopy without appearance of panicle.

$>$ Panicle weight and number; grain weight $5 \mathrm{~g}$ per panicle, 270 - 300 panicles $\mathrm{m}^{-2}$.

$>$ Leaf area index (LAI): The LAI of top three leaves is about 6

$>$ Harvest index: about 0.55

\section{Heterosis Breeding}

Rice hybrids with a yield advantage of about $10 \%$ - 15\% over best inbred varieties were introduced in China in mid 1970s and are now planted to about $45 \%$ of the rice land in that country. Rice hybrids adapted to tropics have now been bred at IRRI and by NARS and show similar yield advantage. The increased yield advantage of tropical rice hybrids is due to increased biomass, higher spikelet number and to some extent higher grain weight. 
Increased adoption of hybrids in the tropics should contribute to increased productivity.

\subsection{Improving Parental Lines to Increase Efficiency of Hybrid Rice Breeding}

Because of the potential of hybrid rice to increase rice production and productivity, many countries are currently working to exploit the benefits of this technology. The major problems in hybrid rice breeding are the limited number of parental lines with specific desirable traits, a lower frequency of maintainers and restorers among elite breeding lines, the narrow genetic base, a lack of resistance to biotic stresses, and poor grain quality of some parental lines. Therefore, improving parental lines must be an integral part of hybrid rice breeding to develop heterotic hybrids and improve breeding efficiency. The frequency of maintainers and restorers has been significantly increased after initiating specific maintainer and restorer breeding programs. Diverse parental lines with better grain quality and multiple resistances have been developed in China and at IRRI. Random mating of composite populations of maintainers and restorers developed at IRRI has helped to widen the genetic base of parental lines. Transferring restorer genes into tropical japonicas and incorporating wide compatibility genes into promising elite lines are considered essential to developing indica/japonica hybrids. Thermosensitive genic male sterile lines are being generated in indica, tropical japonica, and basmati genetic backgrounds. Anther culture and marker-aided selection can be deployed to expedite the parental line improvement program.

\subsection{Using Tropical Japonica Germplasm to Enhance Heterosis in Rice}

The current level of heterosis $\left(15 \%\right.$ - 20\% or $\left.0.75-1.0 t \cdot h a^{-1}\right)$ in indica rice hybrids developed for the tropics is economically viable, but a higher level would be more attractive. Studies at IRRI have showed a higher heterosis for yield in tropical japonica/indica crosses than in indica/indica crosses. Increased heterosis for yield in tropical japonica/indica crosses is possible only if they exhibit normal spikelet fertility. Several tropical japonica rice cultivars that possess the wide compatibility (WC) gene have been identified. Suitable parental lines in improved tropical japonica germplasm possessing the WC gene are being bred at IRRI. These parental lines would help to develop heterotic tropical japonica/indica hybrids.

\subsection{The Wide Compatibility System}

The genetic basis for hybrid sterility is presented with methods to analyze it. Several independent loci have been identified that cause partial abortion of female gametes carrying an allele in heterozygotes. Similar genetic mechanisms were also identified for male gametes that affect pollen fertility. The hybrid sterility in indica/japonica crosses was mostly attributed to an S-5 locus. Therefore, a single wide compatibility allele can be used to obtain fertile hybrids between the two groups. But hybrid sterility in crosses between rice cultivars from the Indian subcontinent and other areas was controlled by several loci, as detected in Basmati 370 crosses. In hybrid rice breeding, hybrid sterility genes in cytoplasmic male sterile lines affect the screening of potential restorers but not maintainers. It is important to analyze hybrid sterility genes in maintainers to achieve enhanced heterosis in hybrid rice breeding.

\section{Male Sterility}

In rice, there are three major types of CMS/restoration systems, including CMS-BT (borotype), CMS-WA (wild abortive), and CMS-HL (Honglian). The first commercially used CMS-WA germplasm was discovered by Chinese scientist Long Ping Yuan in 1970's and was used to develop the three-line system hybrid rice. As a gametophytic system, CMS-BT is the most widely investigated rice CMS system at the genetic level, and is originally derived from the cytoplasm of an indica rice variety Chinsurash BoroII. Recently, Dr. Yaoguang Liu's laboratory published the results of a study, in which they cloned the CMS and two Rf genes in the CMS-BT/restoration system and elucidated the molecular mechanism for male sterility and fertility restoration [10]. This is a significant contribution to hybrid rice dedicated by Chinese scientists. A number of fertility restorer genes that are involved in other CMS systems have been studied genetically. Two Rf loci, Rf5 and Rf6 (t), responding to CMS-HL, have been located in different regions of chromosome 10 [11]. Both the CMSDT restorer gene Rf-d1 (t) and the CMS-DA restorer gene Rf-d (t) were also detected on chromosome 10 [12] [13]. Two CMS-WA restorer genes Rf3 (t) and Rf4 (t) have been located on chromosomes 1 and 10, respectively [14]. 


\subsection{Diversifying the CMS System to Improve the Sustainability of Hybrid Rice Technology}

Cytoplasmic male sterility (CMS) resulting from nuclear-cytoplasm interaction has been commercially exploited for the production of F1 hybrid seed in a number of crops such as maize, sorghum, sunflower and sugarbeet. More recently, major progress has been made in developing high-yielding hybrid rice varieties based on the CMS system, occupying over 18 million hectares in China. The first CMS line used to develop commercial F1 hybrids were developed in China in 1973 from a single male sterile plant (Oryza sativa f. spontanea) designated as wild abortive (WA). Since then, more than 20 CMS sources have been developed from various accessions of cultivated rice and wild species. A large number of CMS lines have been produced in China, at IRRI, and in several other countries from these cytosterility systems. But $95 \%$ of the total area planted to hybrid rice has a single CMS source, WA cytoplasm. This cytoplasmic uniformity of hybrid varieties could result in disease epidemics, such as the outbreak of Southern corn blight due to Helminthosporium maydis on US maize hybrids carrying T-type cytoplasm. To overcome the danger of genetic vulnerability of hybrid rice to diseases and insects, we urgently need to diversify the cytoplasm of the male sterility sources. Conventional backcrossing and somatic cell hybridization are possible avenues to achieve diversification using cultivated and wild species as CMS donors. Two major problems are 1) the lack of efficient techniques for characterizing CMS sources and 2) non-availability of effective restorers, particularly when the cytoplasmic donors (wild species) and recipient parents are distantly related. Under such situations, the donor species itself should be explored as a possible restorer. CMS sources are distinguished from each other on the basis of the fertility of crosses of CMS lines with restorers.

These procedures are laborious and fertility is affected by environment. Advances in molecular biology offer potential to develop precise, reliable, and quick molecular techniques to characterize different CMS sources. Fertile and male sterile lines including different sources of CMS can be distinguished from each other using molecular diagnostic probes based on the restriction endonuclease fragment pattern of mtDNA, including the nature of mitochondrial protein products and ultrastructure of the mitochondrial genome. But the role of these elements in producing cytosterility is not well understood. Protoplast fusion offers promise to produce cybrids and new alloplasmic male sterile lines. Moreover, this technology can further enhance efficiency through the quick transfer of CMS from one source to other elite breeding lines. Otherwise, this requires 5 - 6 generations of conventional backcrossing. Both two-line (photoperiod-sensitive and thermosensitive genic male sterility) and one-line (apomixis) systems offer a good alternative to the current three-line (CMS) system for producing hybrid seed. But until these systems become available for commercial production of hybrid seed, CMS continues to be the best strategy and thus needs diversification for the sustainability of hybrid rice technology.

\subsection{Advances in Two-Line Hybrid Rice Breeding}

The discovery of environment-sensitive genic male sterility in rice led to the development of a simpler and more efficient two-line hybrid breeding system compared with the cytoplasmic male sterility or three-line system. Several elite photoperiod-sensitive (PGMS) and thermosensitive genic male sterile (TGMS) lines have been developed in China. The commercial two-line hybrids developed using these lines occupied about 330,000 ha in 1996. Multiplying PGMS and TGMS lines in a pure form requires some special handling. These methods have been developed in China. Similar methods of seed production have been adopted for both two-line and three-line hybrids. The key point is to determine the time when a PGMS or TGMS line will show complete sterility for about $1 \mathrm{mo}$ at a given location. Seed yield of two-line hybrids in China is $2.25-3.0 \mathrm{t} \cdot \mathrm{ha}^{-1}$. Under tropical conditions, in which day length differences are marginal, the TGMS system is considered to be more useful than the PGMS system. Genetic analysis at IRRI confirmed the monogenic recessive control of the TGMS trait. The TGMS gene of the IRRI mutant, IR32364 TGMS, was found to be non-allelic to the TGMS genes identified in China (tms 1) and Japan (tms 2). IRRI has developed some TGMS lines in indica rice that possess the tms 2 gene; these lines are being evaluated in national agricultural systems. As expected, the TGMS system gave a higher frequency of heterotic hybrids than the CMS system.

\subsection{Breeding and Characterizing Indica PGMS and TGMS Lines in China}

Hubei photoperiod-sensitive genic male sterile (PGMS) rice Nongken 58S, which was used as the donor of genic male sterile genes, was crossed, backcrossed, and multi-crossed with various target indica varieties. Sterile 
plants were selected under different environments. In the past 15 years, eight thermosensitive genic male sterile (TGMS) lines and four PGMS lines were developed. The characteristic response of these lines to photoperiod and temperature was studied under various environments in the field and in phytotrons. The results showed that most of them had a completely stable sterile period of about 45 days at Wuhan. The temperature-sensitive stage ranged from the differentiating stage of the pollen mother cell to the early ripe stage of pollen. The critical temperature points (CTP) of fertility alteration varied in different TGMS lines: $26.5^{\circ} \mathrm{C}$ (daily mean) for W6154S, W6184S, W6111S, W6417S, and W8103S; $25.5^{\circ} \mathrm{C}$ for W9046S and W9056S; and $24^{\circ} \mathrm{C}$ for W91607S. The fertility expression of PGMS lines was controlled simultaneously by photoperiod and temperature. PGMS line W7415S had a CTP of $26^{\circ} \mathrm{C}$ and a critical photoperiod point (CPP) of $13.5 \mathrm{~h}$. The CTP and CPP for W9451S and W9461S were $24^{\circ} \mathrm{C}$ and $14.0 \mathrm{~h}$, and for W9593S they were $24^{\circ} \mathrm{C}$ and $13.0 \mathrm{~h}$, respectively. A practical and effective procedure for breeding PGMS and TGMS lines has been established.

\section{Wide Hybridization}

Crop gene pools are widened through hybridization of crop cultivars with wild species, weedy races as well as intra-subspecific crosses. Such gene pools are exploited for improving many traits including yield. Reference [15] reported that a quarter of lines from BC2-BC4 segregants from the Avena sativa $\times$ Avena sterilis crosses were significantly higher in grain yield than the cultivated recurrent parent. Nine lines from this study when tested over years and sites had agronomic traits similar to the recurrent parent and $10 \%-29 \%$ higher grain yield. The higher yield potential of these inter-specific derivatives was attributed to higher vegetative growth rates or early seedling vigor.

Reference [16] reported that some backcross derivates from a cross between an Oryza rufipogon accession from Malaysia and cultivated rice, out yielded the recurrent parent by as much as $18 \%$. They identified two QTL from wild species with major contribution to yield increase. These QTL are now being transferred to several modern semi-dwarf varieties.

\section{Wide Hybridization for Disease and Insect Resistance}

Wild species of rice are a rich source of genes for resistance breeding. For example, none of the cultivated rice was found to be resistant to grassy stunt. Oryza nivara, a wild species closely related to cultivated rice was found to be resistant and the dominant gene for resistance was transferred to improved germplasm through backcrossing. This gene for resistance has been incorporated into many widely grown varieties. When genes are to be transferred from more distantly related species, special techniques such as embryo rescue are employed to reproduce inter-specific hybrids. Reference [17] transferred genes for resistance to three biotypes of brown plant hopper from $O$. officinalis to an elite breeding line. Reference [18] transferred genes for resistance to brown plant hopper from O. australiensis to cultivated rice. Similarly genes for resistance to blast and bacterial blight have been transferred from O. minuta to improved rice germplasm [19].

\section{Genetic Engineering}

Protocols for rice transformation have been developed which allow transfer of foreign genes from diverse biological systems into rice. Direct DNA transfer methods such as protoplast based [20] and biolistic as well as Agrobacterium-mediated [21] are being used for rice transformation. Major targets for rice improvement through transformation are disease and insect resistance.

As early as 1987, genes encoding for toxins from Bacillus thuringiensis (BT) were transferred to tomato, tobacco and potato, where they provided protection against Lepidoptern insects. A major target for BT deployment in transgenic rice is the yellow stem borer. This pest is widespread in Asia and causes substantial crop losses. Improved rice cultivar are either susceptible to the insect or have only partial resistance. Thus BT transgenic rice has much appeal for controlling the stem borer. Codon optimized BT genes have been introduced into rice and show excellent levels of resistance in the laboratory and greenhouse [22]. Bt rices have also been tested under field conditions in China [23] and have excellent resistance to diverse populations of yellow stem borer. Besides BT genes, other genes for insect resistance such as those for proteinase inhibitors, $\alpha$-amylase inhibitors and lectins are also beginning to receive attention. Insects use diverse proteolytic or hydrolytic enzymes in their digestive gut for the digestion of food proteins and other food components. Plant derived proteinase inhibitors or 
$\alpha$-amylase inhibitors are of particular interest because these inhibitors are a part of the natural plant defense system against insect predation. Reference [24] reported tansgenic rice carrying cowpea trypsin inhibitor (Cpti) gene with enhanced resistance against striped stem borer and pink stem borer.

Several viral diseases cause serious yield losses in rice. A highly successful strategy termed coat protein (CP) mediated protection has been employed against certain viral diseases such as tobacco mosaic virus in tobacco and tomato. A coat protein gene from rice strip virus was introduced into two japonica varieties by electroporation of protoplasts [25]. The resultant transgenic plants expressed CP at high level and exhibited a significant level of resistance to virus infection and the resistance was inherited to the progenies.

\section{Transgenic Rice for Improved Nutritional Quality—Golden Rice}

Malnutrition disorders are the cause of 24,000 deaths a day. "Golden Rice” represents a genetic engineering concept for the development of nutrient-dense staple crops which can make an important contribution to the reduction of malnutrition in developing countries. Major micronutrient deficiency disorders concern protein, energy, iron, zinc, vitamin A and iodine. These deficiencies are especially severe in countries where rice is the major staple.

Rice contains neither b-carotene (provitamin A) nor C40 carotenoid precursors in its endosperm. Rice in its milled form (as it is usually consumed) is therefore entirely without vitamin A and its carotenoid precursors. Millions of rice consumers who depend on rice for a large proportion of their calories suffer from vitamin A deficiency. Reference [26] produced transgenic rice (Golden Rice) with the provitamin A (b-carotene) biosynthetic pathway engineered into its endosperm. Agrobacterium-mediated transformation was applied to introduce three genes: phytoene synthase (psy), phytoene desaturase (crt1) and lycopene cyclase (lcy). HPLC (high performance liquid chromatography) analysis revealed the presence of b-carotene in transgenic seeds. The transformed rice Taipei 309 is no longer cultivated. Efforts are now underway at IRRI to transfer the genes for b-carotene into widely grown varieties, such as IR 64, through conventional backcrossing and transformation.

Reference [27] introduced the entire coding sequence of the soybean ferritin gene into kita-ake, a rice cultivar via Agrobacterium-mediated transformation. The introduced ferritin gene was regulated by the rice seed storage protein glutelin promoter, GluB-1, and terminated by the Nos polyadenylation signal. Synthesis of soybean ferritin protein was confirmed in each of the transformed rice seeds by western blot analysis, and specific accumulation in endosperm was determined by immunological tissue printing. The iron content of T1 seeds was up to three times higher than in untransformed seeds.

\section{Molecular Marker Assisted Breeding}

Numerous genes for disease and insect resistance are repeatedly transferred from one varietal background to the other. Most genes behave in dominant or recessive manner and require time consuming efforts to transfer. Sometimes the screening procedures are cumbersome and expensive and require large field space. If such genes can be tagged by tight linkage with molecular markers, time and money can be saved in transferring these genes from one varietal background to another. The presence or absence of the associated molecular marker indicates at an early stage, the presence or absence of the desired target gene. A molecular marker very closely linked to the target gene can act as a "tag" which can be used for indirect selection of target gene.

Two of the most serious and widespread diseases in rice production are rice blast caused by the fungus Pyrcularia oryzae, and bacterial blight caused by Xanthomonas oryzae pv. oryzae. Development of durable resistance to these diseases is the focus of a coordinated effort at IRRI using molecular marker technology. Efforts to detect markers closely linked to bacterial blight resistance genes have taken advantage of the availability of near isogenic lines having single genes for resistance. Segregating populations were used to confirm co-segregation between RFLP markers and genes for resistance. Protocols for converting RFLP markers into PCR based markers and using the PCR markers in marker-aided selection have been established [28]. The PCR markers were also used for pyramiding genes for resistance to bacterial blight. Thus xa4, x5, xa13, and Xa21 were combined into same breeding line [29]. The pyramided lines showed a wider spectrum and higher level of resistance than lines with only a single gene for resistance. MAS has also been employed for moving genes from pyramided lines into new plant type [30] as well as into improved varieties grown in India [31].

Novel alleles and genetic diversity widely exist in wild relatives of cultivated plants. For example, wild rela- 
tives of rice within the genus Oryza are not only a rich source of information on the origins of variation within the genus but also a viable source of a wide variety of agronomically important germplasm for future breeding. To fill the gulf between national research programs and breeding applications in developing countries, an international program, Challenge Programs was established to unlock the genetic diversity existing in a wide spectrum of germplasm collections. Molecular markers have been proven particularly useful for accelerating the backcrossing of a gene or QTL from exotic cultivars or wild relatives into an elite cultivar or breeding line. Favorable genes or alleles from wild species of rice have been detected after backcrossing to elite cultivars [32]. Similarly, this approach can identify alleles from exotic cultivars that result in improved phenotype, even though the parent may not possess inferior phenotype for this trait. This approach is thought to be promising in rice because a number of rice cultivars are widely grown for their adaptation, stable performance, and desirable grain quality. Reference [33] used such an approach to transfer the bacterial blight resistance gene Xa21 into Minghui 63, a widely used parent for hybrid rice production in China. Reference [34] used a similar approach to introgress two QTLs controlling resistance to rice yellow mottle virus into the cultivar IR64. Such approaches, however, can only sample a small number of accessions.

\subsection{Breeding for Durable Resistance}

Full yield potential of modern rice varieties is not realized because of the toll taken by the attack of disease and insect organisms. It is estimated that diseases and insects cause yield losses of up to $25 \%$ annually. Genetic improvement to incorporate durable resistance to pests is the preferred strategy to minimize these losses. There is no cost to farmers and resistant cultivars are easily adopted and disseminated unlike "knowledge based" technologies. Also concern for the environment has become an important public policy issue and pest management methods that minimize the use of crop protection chemicals are increasingly finding favor.

\subsection{Biotic Stress Resistance}

To date, two blight-resistant genes, Xa26 and Xa13, have been cloned by Chinese scientists [35]. Xa26 on chromosome 11 encodes an leucine rich repeat (LRR) receptor kinase-like protein [36]. xa13, a recessive allele conferring disease resistance against bacterial blight, plays a key role in both disease resistance and pollen development, and represents a new type of plant disease resistance. The dominant allele, Xa13, is required for both bacterial growth and pollen development. Promoter mutations in Xa13 cause down-regulation of expression during host pathogen interaction, resulting in the fully recessive xa13 that confers race-specific resistance [35]. Also five other genes (Xa4, Xa2, Xa-7, Xa-23 and Xa-25) with resistance to bacterial blight have been mapped or delimited to a narrow physical interval [37] [38].

Insect-resistance studies are mainly carried out on brown plant hopper (BPH) and white brown plant hopper (wbph). Reference [39] fine-mapped a resistance gene, which was designated tentatively as bph19 (t), against $\mathrm{BPH}$ on chromosome 3. Reference [40] delimited bph15 to a region of $47 \mathrm{~kb}$ on chromosome 4 . Another three BPH-resistant genes, Bph12 (t), bph2, bph9 and a WBPH-resistant gene wbph6 (t) were located on chromosomes $4,12,12$ and 11 , respectively [41].

\section{Conclusion}

Improvement in the yield potential of rice is the major strategy to increase world rice production. Various strategies to increase the yield potential include: conventional hybridization, ideotype breeding, heterosis breeding, male sterility, wide hybridization, genetic engineering and molecular marker assisted breeding. Conventional breeding is still a widely used strategy for developing crop varieties with a higher yield potential. The integration of molecular biology, genomic research, transgenic breeding and molecular marker applications with conventional plant breeding practices has created the foundation for molecular plant breeding and will certainly accelerate rice improvement programs across the world including India. Molecular-assisted selection (MAS) has become integral component of germplasm improvement. A large number of genes for various traits have been tagged with molecular markers to apply MAS for trait improvement. Map-based cloning has resulted in isolation of several genes for resistance to biotic and abiotic stresses as well as yield-related traits. This has opened the possibility of applying MAS for yield enhancement. Recombinant DNA technology has resulted in production of transgenic rice with new genetic traits and for resistance to biotic and abiotic stresses. 


\section{References}

[1] Peng, S.R., Laza, C., Visperas, R.M., Sanico, A.L., Cassman K.G. and Khush G.S. (2000) Grain Yield of Rice Cultivars and Lines Developed in the Philippines since 1966. Crop Science, 40, 307-314. http://dx.doi.org/10.2135/cropsci2000.402307x

[2] Sarkarung, S., Singh, O.N., Roy, J.K., Vanavichit, A. and Bhekasut, P. (1995) Breeding Strategies for Rainfed Lowland Ecosystem. Proc. Int. Rice Res. Conf., Manila, IRRI, 709-720.

[3] Program Report for 1994 IRRI (1995) International Rice Research Institute, Manila, 309.

[4] Mackill, D.J. and Xu, K. (1996) Genetics of Seedling-Stage Submergence Tolerance in Rice; Rice Genetics III. In: Khush, G.S. Ed., Proceedings of Third International Rice Genetics Symposium, IRRI, Manila, 607-612.

[5] Kenong, X., Ronald, P.C. and Mackill, D.J. (1997) Development of High Resolution Map around the Rice Submergence Tolerance Locus Sub I. General Meeting of the International Program on Rice Biotechnology, Malacca, 158.

[6] Chandler Jr., R.F. (1969) Plant Morphology and Stand Geometry in Relation to Nitrogen. In: Eastin, J.D., Haskin, F.A., Sullivan, C.Y. and Van Baul, C.H.M., Eds., Physiological Aspects of Crop Yield, ASA Publication, Madison, 265-285.

[7] IRRI (1989) IRRI towards 2000 and beyond. International Rice Research Institute, P.O. Box 933, Manila.

[8] Khush, G.S. (1995) Breaking the Yield Barrier of Rice. GeoJournal, 35, 329-332. http://dx.doi.org/10.1007/BF00989140

[9] Peng, S., Khush, G.S., Virk, P., Tang, Q. and Yingbin, Z. (2008) Progress in Ideotype Breeding to Increase Rice Yield Potential. Field Crops Research, 108, 32-38. http://dx.doi.org/10.1016/j.fcr.2008.04.001

[10] Wang, Z.H., Zou, Y.J., Li, X.Y., Zhang, Q.Y., Chen, L.T. and Wu, H. (2006) Cytoplasmic Male Sterility of Rice with Boro II Cytoplasm Is Caused by a Cytotoxic Peptide and Is Restored by Two Related PPR Motif Genes via Distinct Modes of mRNA Silencing. Plant Cell, 18, 676-687. http://dx.doi.org/10.1105/tpc.105.038240

[11] Liu, X.Q., Xu, X., Tan, Y.P., Li, S.Q., Hu, J. and Huang, J.Y. (2004) Inheritance and Molecular Mapping of Two Fertility-Restoring Loci for Honglian Gametophytic Cytoplasmic Male Sterility in Rice (Oryza sativa L.). Molecular Genetics and Genomics, 271, 586-594. http://dx.doi.org/10.1007/s00438-004-1005-9

[12] Xie, J.K., Zhuang, J.Y., Fan, Y.Y., Tu, G.Q., Xia, Y.W. and Zheng, K.L. (2001) Mapping of a Fertility-Restoring Gene for Dwarf-Wild-Abortive CMS in Rice. Chinese Journal of Rice Science, 15, 161-164.

[13] Tan, X.L., Tan, Y.L., Zhao, Y.H., Zhang, X.M., Hong, R.K. and Jin, S.L. (2004) Identification of the Rf Gene Conferring Fertility Restoration of the CMS Dian-Type 1 in Rice by Using Simple Sequence Repeat Markers and Advanced Inbred Lines of Restorer and Maintainer. Plant Breeding, 123, 338-341. http://dx.doi.org/10.1111/j.1439-0523.2004.01004.x

[14] Yang, H.Y., Ren, X., Weng, Q.M., Zhu, L.L. and He, G.C. (2002) Molecular Mapping and Genetic Analysis of a Rice Brown Planthopper (Nilaparvata lugens) Resistance Gene. Hereditas, 136, 39-43. http://dx.doi.org/10.1034/j.1601-5223.2002.1360106.x

[15] Lawerence, P.L. and Frey, K.J. (1976) Backcross Variability for Grain Yield in Species Crosses (Avena sativa L. $\times$ A. sterilis L.). Euphytica, 24, 77-85. http://dx.doi.org/10.1007/BF00147171

[16] Xiao, J., Grandillo, S., Ahn, S.N., McCouch, S.R. and Tanksley, S.D. (1996) Genes from Wild Rice Improve Yield. Nature, 38, 1223-224. http://dx.doi.org/10.1038/384223a0

[17] Jena, K.K. and Khush, G.S. (1990) Introgression of Genes from Oryza officinalis Well ex Watt to Cultivated Rice, O. sativa L. Theoretical and Applied Genetics, 80, 737-745. http://dx.doi.org/10.1007/bf00224186

[18] Multani, D.S., Jena, K.K., Brar, D.S., Delos Reyes, B.G., Angeles, E.R. and Khush, G.S., (1994) Development of Monosomic Alien Addition Lines and Introgressions of Genes from Oryza australiensis Domin. to Cultivated Rice O. sativa L. Theoretical and Applied Genetics, 88, 102-109. http://dx.doi.org/10.1007/BF00222401

[19] Brar, D.S. and Khush, G.S. (1997) Wide Hybridization for Rice Improvements: Alien Gene Transfer and Molecular Characterization of Introgression. In: Jones, M.P., Dingkhun, M., Johnson, D.E. and Fagade, S.O., Eds., Inter-Specific Hybridization: Progress and Prospect WARDA, 01BP2551, Cote d' voire, Bouake, 21-29.

[20] Datta, S.K., Peterhaus, A., Datta, K. and Potrykus, I. (1990) Genetically Engineered Fertile Indica Rice Recovered from Protoplasts. Nature Biotechnology, 8, 736-740. http://dx.doi.org/10.1038/nbt0890-736

[21] Hei, Y., Ohta, S., Komari, T. and Kumashiro, T. (1994) Efficient Transformation of Rice (Oryza sativa L.) Mediated by Agrobacterium and Sequence Analysis of the Boundaries of T-DNA. The Plant Journal, 6, 271-282. http://dx.doi.org/10.1046/j.1365-313X.1994.6020271.X

[22] Datta, S.K., Torrizo, L., Tu, J., Oliva, N. and Datta, K. (1997) Production and Molecular Evaluation of Transgenic Rice Plants. IRRI Discussion Paper Series No. 21, International Rice Research Institute, Manila.

[23] Tu, J., Zhang, G., Datta, K., Xu, C., He, Y., Zhang, Q., Khush, G.S. and Datta, S.K. (2000) Field Performance of 
Transgenic Elite Commercial Hybrid Rice Expressing Bacillus thuringensis Endoprotein. Nature Biotechnology, 18, 1101-1104. http://dx.doi.org/10.1038/80310

[24] Xu, D., Xue, Q., McElroy, D., Mawal, Y., Hilder, V.A. and Wu, R. (1996) Constitutve Expression of a Cowpea Trypsin Inhibitor Gene CpTi in Transgenic Rice Plants Confers Resistance to Two Major Rice Insect Pests. Molecular Breeding, 2, 167-173. http://dx.doi.org/10.1007/BF00441431

[25] Hayakawa, T., Zhu, Y., Ito, K. and Kimura, Y. (1992) Genetically Engineered Rice Resistant to Rice Stripe Virus, an Insect Transmitted Virus. Proceedings of the National Academy of Sciences of the United States of America, 89, 98659869. http://dx.doi.org/10.1073/pnas.89.20.9865

[26] Ye, X., Al-Babili, S., Kloti, A., Zhang, A., Lucca, P., Beyer, P. and Potrykus, I. (2000) Engineering the Provitamin A ( $\beta$-Carotene) Biosynthetic Pathway into (Carotenoid-Free) Rice Endosperm. Science, 287, 303-305. http://dx.doi.org/10.1126/science.287.5451.303

[27] Goto, F., Yoshihara, T., Shigemoto, N., Toki, S. and Takaiwa, F. (1999) Iron Fortification of Rice Seed by the Soybean Ferritin Gene. Nature Biotechnology, 17, 282-286. http://dx.doi.org/10.1038/7029

[28] Zheng, K., Huang, N., Bennett, J. and Khush, G.S. (1995) PCR-Based Marker-Assisted Selection in Rice Breeding. IRRI Discussion Paper Series No. 12, International Rice Research Institute, Manila.

[29] Huang, N., Angeles, E.R., Domingo, J., Magpantay, G., Singh, G., Zhang, G., Kumaravadivel, N., Bennett, J. and Khush, G.S. (1997) Pyramiding of Bacterial Blight Resistance Genes in Rice: Marker Assisted Selection Using RFLP and PCR. Theoretical and Applied Genetics. 95, 313-320. http://dx.doi.org/10.1007/s001220050565

[30] Sanchez, A.C., Brar, D.S., Huang, N., Li, Z. and Khush, G.S. (2000) STS Marker-Assisted Selection for Three Bacterial Blight Resistance Genes in Rice. Crop Science, 40, 792-797. http://dx.doi.org/10.2135/cropsci2000.403792x

[31] Singh S., Sidhu, J.S., Huang, N., Vikal, Y., Li, Z., Brar, D.S., Dhaliwal, H.S. and Khush, G.S. (2001) Pyramiding Three Bacterial Blight Resistance Genes (xa5, xa13 and Xa21) Using Marker-Assisted Selection into Indica Rice Cultivar PR106. Theoretical and Applied Genetics, 102, 1011-1015. http://dx.doi.org/10.1007/s001220000495

[32] Moncada, P., Martinez, C.P., Borrero, J., Chatel, M., Gauch, H., Guimaraes, E., Tohme, J. and McCouch, S.R. (2001) Quantitative Trait Loci for Yield and Yield Components in an Oryza sativa $\times$ Oryza rufipogon BC2F2 Population Evaluated in an Upland Environment. Theoretical and Applied Genetics, 102, 41-52. http://dx.doi.org/10.1007/s001220051616

[33] Chen, S., Lin, X.H., Xu, C.G. and Zhang, Q.F. (2000) Improvement of Bacterial Blight Resistance of “Minghui 63”, an Elite Restorer Line of Hybrid Rice, by Molecular Marker-Assisted Selection. Crop Science, 40, 239-244. http://dx.doi.org/10.2135/cropsci2000.401239x

[34] Ahmadi, N., Albar, L., Pressoir, G., Pinel, A., Fargette, D. and Ghesquiere, A. (2001) Genetic Basis and Mapping of the Resistance to Rice Yellow Mottle Virus. III. Analysis of QTL Efficiency in Introgressed Progenies Confirmed the Hypothesis of Complementary Epistasis between Two Resistance QTLs. Theoretical and Applied Genetics, 103, 10841092. http://dx.doi.org/10.1007/s001220100642

[35] Chu, Z.H., Yuan, M., Yao, J.L., Ge, X.J., Yuan, B. and Xu, C.G. (2006) Promoter Mutations of an Essential Gene for Pollen Development Result in Disease Resistance in Rice. Genes \& Development, 20, 1250-1255. http://dx.doi.org/10.1101/gad.1416306

[36] Sun, L.H., Wang, C.M., Su, C.C., Liu, Y.Q., Zhai, H.Q. and Wan, J.M. (2006). Mapping and Marker-Assisted Selection of a Brown Planthopper Resistance Gene Bph2 in Rice (Oryza sativa L.). Journal of Genetics and Genomics, 33, 717-723. http://dx.doi.org/10.1016/s0379-4172(06)60104-2

[37] He, Q., Li, D.B., Zhu, Y.S., Tan, M.P., Zhang, D.P. and Lin, X.H. (2006) Fine Mapping of Xa2, a Bacterial Blight Resistance Gene in Rice. Molecular Breeding, 17, 1-6. http://dx.doi.org/10.1007/s11032-005-8698-2

[38] Fan, Y.L., Chen, X.W., Wang, C.L., Zhu, L.H., Zhang, Q. and Zhao, K.J. (2006) Mapping the Rice Bacterial Blight Resistance Gene Xa23 with RFLP Markers and Converting RFLP to STS Marker. Acta Genetica Sinica, 32, 931-935.

[39] Chen, J.W., Wang, L., Pang, X.F. and Pan, Q.H. (2006) Genetic Analysis and Fine Mapping of a Rice Brown Planthopper (Nilaparvata lugens Stål) Resistance Gene Bph19 (t). Molecular Genetics and Genomics, 275, 321-329. http://dx.doi.org/10.1007/s00438-005-0088-2

[40] Yang, H.Y., You, A.Q., Yang, Z.F., Zhang, F.T., He, R.F. and Zhu, L.L. (2004) High-Resolution Genetic Mapping at the Bph15 Locus for brown Planthopper Resistance in Rice (Oryza sativa L.). Theoretical and Applied Genetics, 110, 182-191. http://dx.doi.org/10.1007/s00122-004-1844-0

[41] Su, C.C., Zhai, H.Q., Wang, C.M., Sun, L.H. and Wan, J.M. (2006). SSR Mapping of Brown Planthopper Resistance Gene Bph9 in Kaharamana, an Indica Rice (Oryza sativa L.). Journal of Genetics and Genomics, 33, 262-268. 